\title{
Should Early Mobilization Be Routine in Mechanically Ventilated Patients?
}

\author{
Ulrich H Schmidt MD PhD MBA, Lauren Knecht MD, and Neil R MacIntyre MD FAARC
}

\author{
Introduction \\ Early Mobilization: The Case for Routine Application in Mechanically \\ Ventilated Patients \\ The Supporting Evidence Base \\ How Early, How Often, How Long? \\ Early Mobilization: Concerns and Reasons for Caution \\ Are the Results of the Many Positive Trials Overstated? \\ Early Mobility Entails Patient Risk \\ Early Mobility Programs Require Additional Resources \\ Other Logistical Challenges \\ Conclusions
}

\begin{abstract}
ICU-acquired weakness is a major complication of critical illness requiring mechanical ventilation. Early mobilization has been shown to decrease the negative consequences of ICU-acquired weakness. However, early mobilization might entail risks to the patient. Additional staffing needs might have a negative financial impact. This review examines whether early mobilization should be routinely performed in mechanically ventilated patients. Key words: mobilization; weakness; mechanical ventilation. [Respir Care 2016;61(6):867-875. () 2016 Daedalus Enterprises]
\end{abstract}

\section{Introduction}

Deconditioning and weakness are prevalent problems in survivors of critical illness requiring mechanical ventilation. Intensive care unit (ICU) acquired weakness is characterized by fatigue and profound neuromuscular weak-

Drs Schmidt and Knecht are affiliated with the Department of Anesthesiology, University of California, San Diego, California. Dr MacIntyre is affiliated with the Department of Medicine, Duke University, Durham, North Carolina.

The authors have disclosed no conflicts of interest.

Dr MacIntyre presented a version of this paper at the 54th RESPIRATORY CARE Journal conference, held June 5-6, 2015, in St. Petersburg, Florida.

Correspondence: Ulrich H Schmidt MD PhD MBA, Department of Anesthesiology, University of California, 200 West Arbor Drive, Room 8770, San Diego, CA 92103-8770. E-mail: uschmidt@ucsd.edu.

DOI: $10.4187 /$ respcare.04566 ness that can cause serious functional disability in survivors. ${ }^{1,2}$ Herridge et $\mathrm{al}^{3}$ performed a prospective study of 109 subjects with ARDS. These subjects had significant physical disability 1 y after hospital discharge, with $<50 \%$ of subjects back at work because of persistent fatigue, weakness, and poor functional status. ${ }^{3}$ The disease pathogenesis is complex and multifactorial but is known to be associated with the inflammatory response from severe sepsis and systemic inflammatory response syndrome. Independent of critical illness, bed rest has been shown to increase reactive oxygen species and inflammatory mediators, causing muscle atrophy and protein catabolism, ultimately leading to disuse atrophy, weakness, and functional disability. ${ }^{4}$ Fink et $\mathrm{al}^{5}$ showed in a preclinical rat model that both immobilization and inflammation cause muscle weakness and are additive in their effects. ICUacquired weakness could therefore be described as a result of a combination of insults leading to a cycle of inflammation, disuse, and muscle breakdown, ultimately leading to functional disability (Fig. 1). 


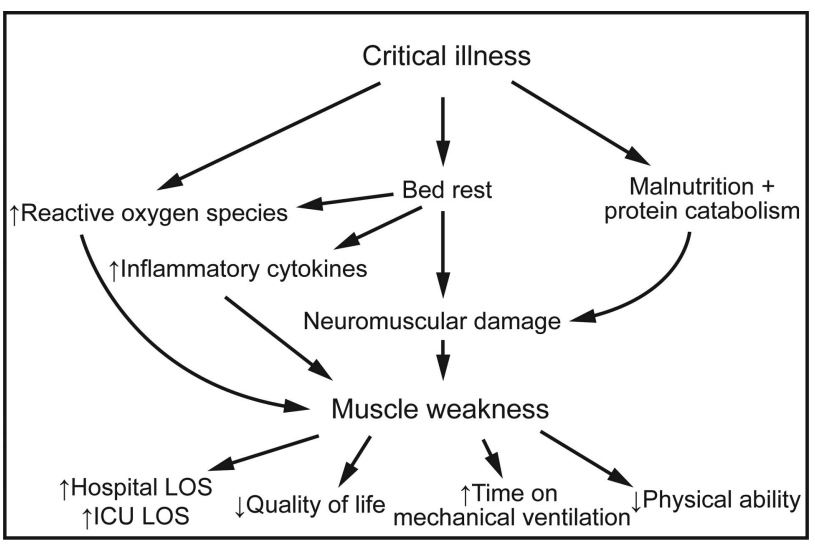

Fig. 1. Mechanisms of ICU-acquired weakness. LOS = length of stay.

ICU-acquired weakness is known to be associated with increased duration of mechanical ventilation, immobilization, and increased ICU and hospital length of stay (LOS). The incidence of ICU-acquired weakness has been reported by observational studies to be as high as $57 \%$, depending on the ICU population studied. ${ }^{6}$ Therefore, ICU-acquired weakness impairs many ICU survivors and is a major public health issue.

Given the deleterious consequences of ICU-acquired weakness, it is not surprising that early mobilization has been promoted to minimize the negative outcome of ICU-acquired weakness. ${ }^{7}$ Early mobilization might, however, have unintended risks leading to negative outcomes. The following review as a pro-con debate will provide the reader with the information to judge whether early mobilization should be routinely performed in mechanically ventilated patients.

\section{Early Mobilization: The Case for Routine Application in Mechanically Ventilated Patients}

\section{The Supporting Evidence Base}

The benefit of physical movement in critically ill patients has been known for decades. In 1995, Griffiths et $\mathrm{al}^{7}$ documented the benefits of passive range-of-motion exercise in decreasing muscle atrophy in subjects with critical illness receiving neuromuscular blockade. The authors used continuous passive motion for 3 -h intervals, compared with a control leg that received routine nursing care. In the continuous passive motion group, they reported less muscle atrophy and a $35 \%$ decrease in fiber area. The fact that passive range-of-motion exercise helps to reduce muscle atrophy led to changes in ICU protocols. ICU nurses in their facility are now required to do passive range-of-motion exercises. However, passive stretching in the bed did not solve the significant problem of protein catabolism.
In 2007, Bailey et $\mathrm{al}^{8}$ investigated whether it was safe and feasible to exercise critically ill subjects while receiving mechanical ventilation. Subjects were included who met the following criteria: ventilated for $>4 \mathrm{~d}$ and physiologically stable in 3 areas: neurologic (respond to command), respiratory $\left(\mathrm{F}_{\mathrm{IO}_{2}}<0.6\right.$, PEEP $\left.<10 \mathrm{~cm} \mathrm{H} 20\right)$, and circulatory (no orthostasis or catecholamine infusions). There were 3 goals of physical activity: sit on the edge of the bed, sit in a chair, or walk down the hall. The team consisted of nurses, respiratory therapists, physical therapists, and critical care technicians. During the study, 103 subjects were enrolled, and there were 1,449 activity events: 233 events were sitting on the edge of the bed, 454 were sitting in a chair, and 762 were recorded as ambulation. Forty-one percent of the events took place in intubated subjects, and $42 \%$ of those events were ambulation. There were $<1 \%$ associated adverse events, which included 5 falls to knees without injury, 4 systolic blood pressure readings $<90 \mathrm{~mm} \mathrm{Hg}, 3$ oxygen saturations $<80 \%$, one feeding tube removal, and one systolic blood pressure $>200 \mathrm{~mm} \mathrm{Hg}$. There were no unplanned extubations, and none of the adverse events led to lengthened hospital stays or the need for additional therapy.

Morris et al $^{9}$ performed a prospective randomized trial investigating whether a protocol of early mobility (within $48 \mathrm{~h}$ of intubation) with a mobility team versus usual care improved patient outcomes and increased the frequency of physical therapy in ICU subjects. The mobility team consisted of a critical care nurse, nursing assistant, and physical therapist and was dedicated to performing the mobility protocol $7 \mathrm{~d}$ /week, whereas the usual care group received physical therapy at the attending physician's discretion. The study included 4 levels of activity, and subjects progressed through them based on consciousness and increased strength, starting with passive range-of-motion exercises, sitting on the edge of the bed, transfers from bed to chair, seated balance exercises, pregait exercises, and ambulation. The results of this study showed decreased mortality in the protocol group compared with the usual care group (12\% vs 18\%), and there were no deaths, near-deaths, or cardiopulmonary resuscitation during physical therapy. There were no adverse events, such as removal of tubes or devices. There was no difference in ventilator-free days; however, ICU LOS for the protocol group was significantly shorter compared with the usual care group ( $5.5 \mathrm{~d}$ vs $6.9 \mathrm{~d}$ ). Similarly, the hospital LOS was also decreased in the protocol group (11.2 d vs $14.5 \mathrm{~d})$. The cost per subject was $\$ 3,000$ less in the protocol group than in the usual care group.

In 2009, Schweickert et al ${ }^{10}$ published a randomized controlled trial that compared scheduled early mobilization in ventilated subjects with physician-initiated mobility therapy. The primary outcome was the ability of subjects to perform the activities of daily living (independent 


\section{Early Mobilization in Mechanically Ventilated Patients}

functional status) by hospital discharge. In addition, the authors included secondary outcomes, such as duration of delirium, number of ventilator-free days, and LOS in the ICU and hospital. The intervention group started physical therapy on the day of trial enrollment, whereas the control group received standard therapy according to physician order. Physical therapy progressed from passive range-ofmotion exercises to more active bed exercises and further on to activities of daily living and walking. The intervention group began therapy 1.5 (range 1-2.1) d after intubation, whereas the control group did not start therapy until 7.4 (range 6-10.9) d after intubation. Return to independent functional status was achieved more commonly in the intervention group, 59\% of subjects compared with only $35 \%$ in the control group. The intervention group also had more ventilator-free days $(23.5 \mathrm{~d}$ vs $21.1 \mathrm{~d})$ and fewer days of delirium ( $2.0 \mathrm{~d}$ vs $4.0 \mathrm{~d}$ ). Serious adverse events were uncommon: one event in 498 physical therapy sessions (desaturation $<80 \%$ ).

Morris et al ${ }^{11}$ looked at hospital readmissions within $1 \mathrm{y}$, in subjects who had been discharged after hospitalization with acute respiratory failure. They used hospital databases and responses from letters mailed to 280 survivors to determine what factors influenced readmission. Among many variables that predicted readmission and death was the lack of early ICU mobility in those subjects. This supports the notion that early mobility helps to decrease hospital costs. Hospital readmissions are a huge burden on yearly hospital cost and an issue that hospitals take great strides to reduce. Early mobilization protocols, if instituted nationwide, could cut readmission costs greatly, decreasing overall hospital costs.

Hodgson and co-workers ${ }^{12}$ addressed whether early mobilization plays a role in decreasing longer-term mortality following a stay in the ICU. These authors observed the current mobilization practice in 12 Australian hospitals, looking at strength of subjects at discharge as well as outcomes at 3- and 6-month follow-up. ${ }^{12}$ Of 192 subjects enrolled, 147 survived to discharge, and 122 subjects $(63.5 \%)$ did not receive any early mobilization. The main reported barriers were intubation and sedation. On followup, subjects who had received early mobilization had higher muscle strength as measured by the Medical Research Council Manual Muscle Test Sum Score compared with subjects who did not receive early mobilization $(50 \pm 11$ vs $42 \pm 10, P=.003$ ).

These studies provide substantial evidence that a protocol for early mobilization is possible and safe, while reducing mortality. When begun early, patients are more likely to return to their independent functional status, with fewer days on the ventilator and a shorter length of ICU delirium.
Table 1. Reported Complications Associated With Early Mobility From 7 Trials

\begin{tabular}{lr}
\hline \hline Sessions & 8,942 \\
Desaturations & 27 \\
Patient-ventilator asynchrony & 19 \\
Falls/unsteadiness & 15 \\
High blood pressure & 13 \\
Arrhythmias & 12 \\
Gastrostomy tube loss & 7 \\
Low blood pressure & 6 \\
Vascular access loss & 3 \\
Endotracheal tube loss & 1 \\
Achilles rupture & 1 \\
\hline
\end{tabular}

\section{How Early, How Often, How Long?}

There is no consensus among experts as to the best time to implement early mobility. Many studies have used inclusion criteria based on a mechanical ventilation time of $<48 \mathrm{~h}$ to $>4 \mathrm{~d}$ (either length of time on the ventilator or length of time anticipated on the ventilator). ${ }^{8,12,13}$ Although studies looking at this issue use the duration of mechanical ventilation as an inclusion criterion, there is no common, predefined, or agreed upon time (in days from admission or intubation) by which physical therapy must be implemented to classify it as early mobilization. Experts agree upon the necessity of patients to meet appropriate physiologic parameters before starting physical therapy. These parameters include the ability to follow commands, stable ventilator settings, and hemodynamic stability. ${ }^{14}$

Because early mobilization has provided benefits in the ICU setting, a continuation of the therapy after transfer out of the ICU seems a logical step. However, the impact of this remains unknown because most studies on early mobilization have concentrated on the ICU setting and have not continued the therapy to the floor.

\section{Early Mobilization: Concerns and Reasons for Caution}

The evidence base supporting benefits from early mobilization above is compelling. The following discussion is more of a cautionary tale, things to be aware of when trying to understand and implement an early mobilization protocol.

\section{Are the Results of the Many Positive Trials Overstated?}

There are several reasons to be cautious about overinterpreting the multiple positive trials. First, true equipoise was probably lacking in many study sites that have long championed early mobility. This can lead to a subtle selection bias toward keeping "good" subjects in the treat- 


\begin{tabular}{|l|l|}
\hline & $\begin{array}{l}\text { Low risk of an adverse event. } \\
\text { Proceed as usual according to each ICU's protocols and procedures. }\end{array}$ \\
\hline $\begin{array}{l}\text { Potential risk and consequences of an adverse event are higher than green, but may } \\
\text { be outweighed by the potential benefits of mobilization. } \\
\text { The precautions or contraindications should be clarified prior to any mobilization } \\
\text { episode. If mobilized, consideration should be given to doing so gradually and } \\
\text { cautiously. }\end{array}$ \\
\hline $\begin{array}{l}\text { Significant potential risk or consequences of an adverse event. } \\
\text { Active mobilization should not occur unless specifically authorized by the treating } \\
\text { intensive care specialist in consultation with the senior physical therapist and senior } \\
\text { nursing staff. }\end{array}$ \\
\hline
\end{tabular}

Fig. 2. Color-coded symbols for mobilization safety criteria. From Reference 14, with permission.

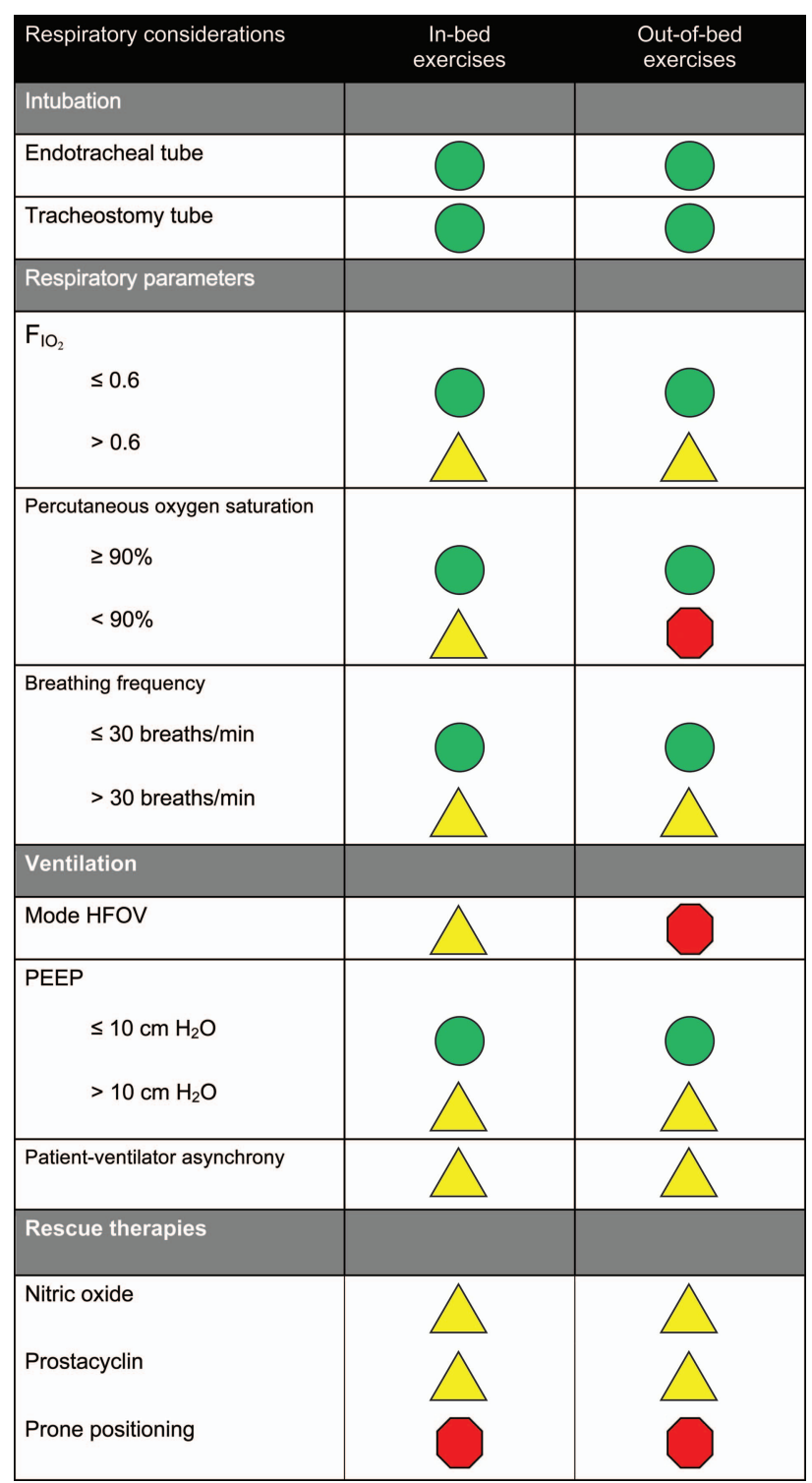

Fig. 3. Respiratory considerations for early mobility. For color coding definitions, see Figure 2. From Reference 14, with permission. ment arm and removing "bad" subjects early. These studies are also unblinded by necessity, and this creates additional potential for bias. Specifically, "believers" may push more aggressive ventilator withdrawal strategies, sedation reduction strategies, and nutritional support and provide other forms of assistance to subjects randomized to early mobility. Indeed, some have suggested that the majority of the benefits attributed to early mobility programs are really a consequence of an aggressive sedation management program, a strategy well documented to facilitate ventilator withdrawal.

One must also be cautious of interpreting the cost savings in these kinds of studies. These purported savings are usually calculated as a reduction in resource consumption due to shorter LOS. Unfortunately, shorter LOS can translate into significant cost reductions only if personnel and infrastructure elements are reduced or eliminated, something very difficult to do in busy ICUs with fixed space costs. Instead, the financial benefit to lower LOS reported in most studies must be tied to some kind of an increase in revenue resulting from more ICU bed availability, where additional patients can be admitted. These studies looking at financial benefits for early mobility programs presume that there will be more turnover and thus more revenue, something that probably occurs but may not.

\section{Early Mobility Entails Patient Risk}

Early mobility is not without its risks, and the complications are very real. One study carefully documented a number of important changes in physiological variables that occur after mobility procedures. ${ }^{15}$ These range from changes in heart rate of up to 15 beats/min, changes in breathing frequency of up to 6 breaths/min, changes in arterial pressure of up to $9 \mathrm{~mm} \mathrm{Hg}$, and drops in saturation $>1$ point. Although these are not huge numbers, they do illustrate that early mobility is associated with physiologic stress. These changes can have important implications in ICU patients who already have limited reserves. 


\begin{tabular}{|c|c|c|}
\hline Cardiovascular considerations & $\begin{array}{l}\text { In-bed } \\
\text { exercises }\end{array}$ & $\begin{array}{l}\text { Out-of-bed } \\
\text { exercises }\end{array}$ \\
\hline \multicolumn{3}{|l|}{ Blood pressure } \\
\hline \multicolumn{3}{|l|}{$\begin{array}{l}\text { Intravenous antihypertensive } \\
\text { therapy for hypertensive } \\
\text { emergency* }\end{array}$} \\
\hline \multicolumn{3}{|l|}{ Mean arterial pressure† } \\
\hline \multicolumn{3}{|l|}{$\begin{array}{l}\text { Below target range and } \\
\text { causing symptoms }\end{array}$} \\
\hline \multicolumn{3}{|l|}{$\begin{array}{l}\text { Below target range despite } \\
\text { support (vasoactive and/or } \\
\text { mechanical) }\end{array}$} \\
\hline \multicolumn{3}{|l|}{$\begin{array}{l}\text { Greater than lower limit of } \\
\text { target range while } \\
\text { receiving no support or low } \\
\text { level support }\end{array}$} \\
\hline \multicolumn{3}{|l|}{$\begin{array}{l}\text { Greater than lower limit of } \\
\text { target range while } \\
\text { receiving moderate level } \\
\text { support }\end{array}$} \\
\hline \multicolumn{3}{|l|}{$\begin{array}{l}\text { Greater than lower limit of } \\
\text { target range on high level } \\
\text { support }\end{array}$} \\
\hline $\begin{array}{l}\text { Known or suspected } \\
\text { severe pulmonary } \\
\text { hypertension }\end{array}$ & & \\
\hline \multicolumn{3}{|l|}{ Cardiac arrhythmias } \\
\hline \multicolumn{3}{|l|}{ Bradycardia } \\
\hline \multicolumn{3}{|l|}{$\begin{array}{l}\text { Requiring pharmacological } \\
\text { treatment (eg, } \\
\text { isoprenaline) or awaiting } \\
\text { emergency pacemaker } \\
\text { insertion }\end{array}$} \\
\hline $\begin{array}{l}\text { Not requiring } \\
\text { pharmacological treatment } \\
\text { and not awaiting } \\
\text { emergency pacemaker } \\
\text { insertion }\end{array}$ & & \\
\hline \multicolumn{3}{|l|}{$\begin{array}{l}\text { Transvenous or } \\
\text { epicardial pacemaker: }\end{array}$} \\
\hline \multicolumn{3}{|l|}{ Dependent rhythm } \\
\hline \multicolumn{3}{|l|}{ Stable underlying rhythm } \\
\hline \multicolumn{3}{|l|}{$\begin{array}{l}\text { Any stable } \\
\text { tachyarrhythmia: }\end{array}$} \\
\hline \multicolumn{3}{|l|}{$\begin{array}{l}\text { Ventricular rate }>150 \\
\text { beats } / \mathrm{min}\end{array}$} \\
\hline \multicolumn{3}{|l|}{$\begin{array}{l}\text { Ventricular rate } 120 \text { to } 150 \\
\text { beats/min }\end{array}$} \\
\hline $\begin{array}{l}\text { Any tachyarrhythmia } \\
\text { with ventricular rate < } \\
120 \text { beats/min }\end{array}$ & & \\
\hline
\end{tabular}

\begin{tabular}{|c|c|c|}
\hline Cardiovascular considerations & $\begin{array}{c}\text { In-bed } \\
\text { exercises }\end{array}$ & $\begin{array}{l}\text { Out-of-bed } \\
\text { exercises }\end{array}$ \\
\hline Devices & & \\
\hline Femoral IABP $\ddagger$ & & \\
\hline ECMO: & & \\
\hline $\begin{array}{l}\text { Femoralł or subclavian } \\
\text { (not single bicaval dual } \\
\text { lumen cannulae) }\end{array}$ & & \\
\hline $\begin{array}{l}\text { Single bicaval dual lumen } \\
\text { cannulae inserted into a } \\
\text { central vein }\end{array}$ & & \\
\hline Ventricular assist device & & \\
\hline $\begin{array}{l}\text { Pulmonary artery catheter } \\
\text { or other continuous } \\
\text { cardiac output monitoring } \\
\text { device }\end{array}$ & & \\
\hline $\begin{array}{l}\text { Other cardiovascular } \\
\text { considerations }\end{array}$ & & \\
\hline $\begin{array}{l}\text { Shock of any cause with } \\
\text { lactate }>4 \mathrm{mmol} / \mathrm{L}\end{array}$ & & \\
\hline $\begin{array}{l}\text { Known or suspected } \\
\text { acute DVT/PE }\end{array}$ & & \\
\hline $\begin{array}{l}\text { Known or suspected } \\
\text { severe aortic stenosis }\end{array}$ & & \\
\hline $\begin{array}{l}\text { Cardiac ischemia (defined as } \\
\text { ongoing chest pain and/or } \\
\text { dynamic EKG changes) }\end{array}$ & & \\
\hline
\end{tabular}

* This may be a yellow (pause) for in-bed activities if the blood pressure is within target range as documented by the medical team.

† Experienced ICU practitioners were considered to have good judgment about the impact of cardiovascular instability and low, medium or high levels of hemodynamic support, on the ability to mobilize a patient is discussed with appropriate experienced ICU staff. The target mean at the decision to is determined by the treating ICU team Cycling and hip flexion may be contrand exercise may need to be modified to limit hip flexion.

Fig. 4. Cardiovascular considerations for early mobility. IABP = intra-aortic balloon pump, ECMO = extracorporeal membrane oxygenation, DVT $=$ deep vein thrombosis, PE = pulmonary embolism, EKG = echocardiogram. For color coding definitions, see Figure 2. From Reference 14, with permission.

These physiologic stresses can produce more serious problems, some of which have been noted above. A summary of 7 studies is given in Table 1 and shows that the most common problem that terminated a mobility procedure was arterial hemoglobin desaturations. ${ }^{16,17}$ Other im- portant problems were arrhythmias, ventilator asynchrony, patient falls, blood pressure changes, loss of various catheters, and one Achilles tendon rupture. These only occurred in a very small number of sessions $(<1 \%)$, but when they occur, they can be significant. As a consequence, monitoring 
is critically important, and this must be performed by personnel trained to know how to respond. As a minimum, heart rate, pulse oximetry, ventilator settings, blood pressure, and alertness/agitation in patients must be carefully monitored during any mobility procedure.

In 2008, the European Respiratory Society and European Intensive Care Medicine Task Force published guidelines for mobilization of patients in the ICU. ${ }^{18}$ These recommendations were based on observational studies and expert opinion. According to these guidelines, patients could only undergo physical therapy after passing a very long checklist of physiologic parameters. Therefore, if a patient falls outside of the list in one or a few areas, he or she is excluded from physical therapy at that time. However, Garzon-Serrano et al ${ }^{19}$ state that these strict barriers might hurt patients by not allowing them to start therapy at an earlier stage in their hospital stay. These authors advocate for allowing the patients to participate in therapy under the care of a health-care provider who can observe and maintain blood pressure, heart rate, and oxygen saturations within reasonable limits. They argue that patients should thus be evaluated on an individual basis rather than by strict exclusion criteria. More data are required to evaluate this.

A more recent consensus group has put together recommendations on safety criteria to consider before embarking on active mobilization of mechanically ventilated, critically ill patients. ${ }^{14}$ These recommendations are presented as a series of color-coded green, yellow, and red situations (Fig. 2). Green means that the consideration should not be a major barrier to mobility, yellow means that specific monitoring strategies should be provided, and red means that the patient should not be subjected to mobility procedures. These are summarized in Figures 3-6.

\section{Early Mobility Programs Require Additional Resources}

Most mobility programs involve several levels of progressive activity, as noted above. Level 1 is simply with the patient lying in bed, level 2 is with the patient sitting on the bed, level 3 is standing and pivoting, and finally level 4 is walking. These all require various levels of additional caregivers. If the patient is simply lying in the bed, most activities can usually be accomplished by the bedside nurse. However, once the patient is sitting on the bed, additional personnel are required. If the patient is standing, there may be more than one person required, and if the person is walking, especially with a ventilator, this may require multiple caregivers.

To address these issues, additional resources are going to be required. Three large centers (Wake Forest University, John Hopkins University, and the University of California at San Francisco) reported the increased need for

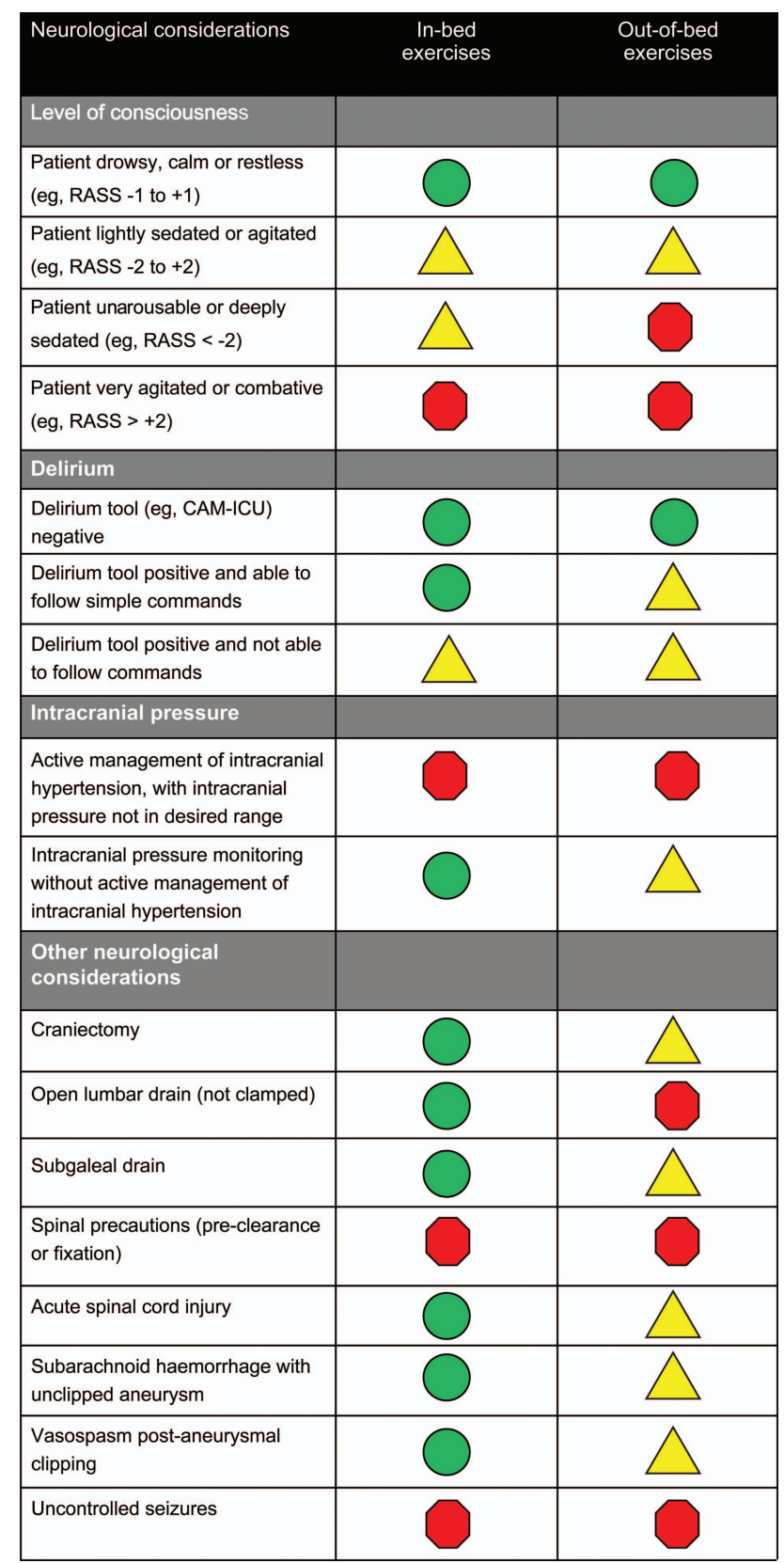

Fig. 5. Neurological considerations for early mobility. RASS = Richmond Agitation Assessment Scale, CAM-ICU = confusion assessment method for the ICU. For color coding definitions, see Figure 2. From Reference 14, with permission.

resources for carrying out mobility programs..$^{20}$ At Wake Forest University, 7-d/week mobility is provided. To do this, one additional registered nurse, one additional nursing assistant, one additional physical therapist, and a manager were needed. At Johns Hopkins, which provides 6-d/week mobility, one physical therapist, one occupational therapist, one technician, one coordinator, one parttime assistant coordinator, and 2 new wheel chairs were added. At the University of California at San Francisco, 


\section{Early Mobilization in Mechanically Ventilated Patients}

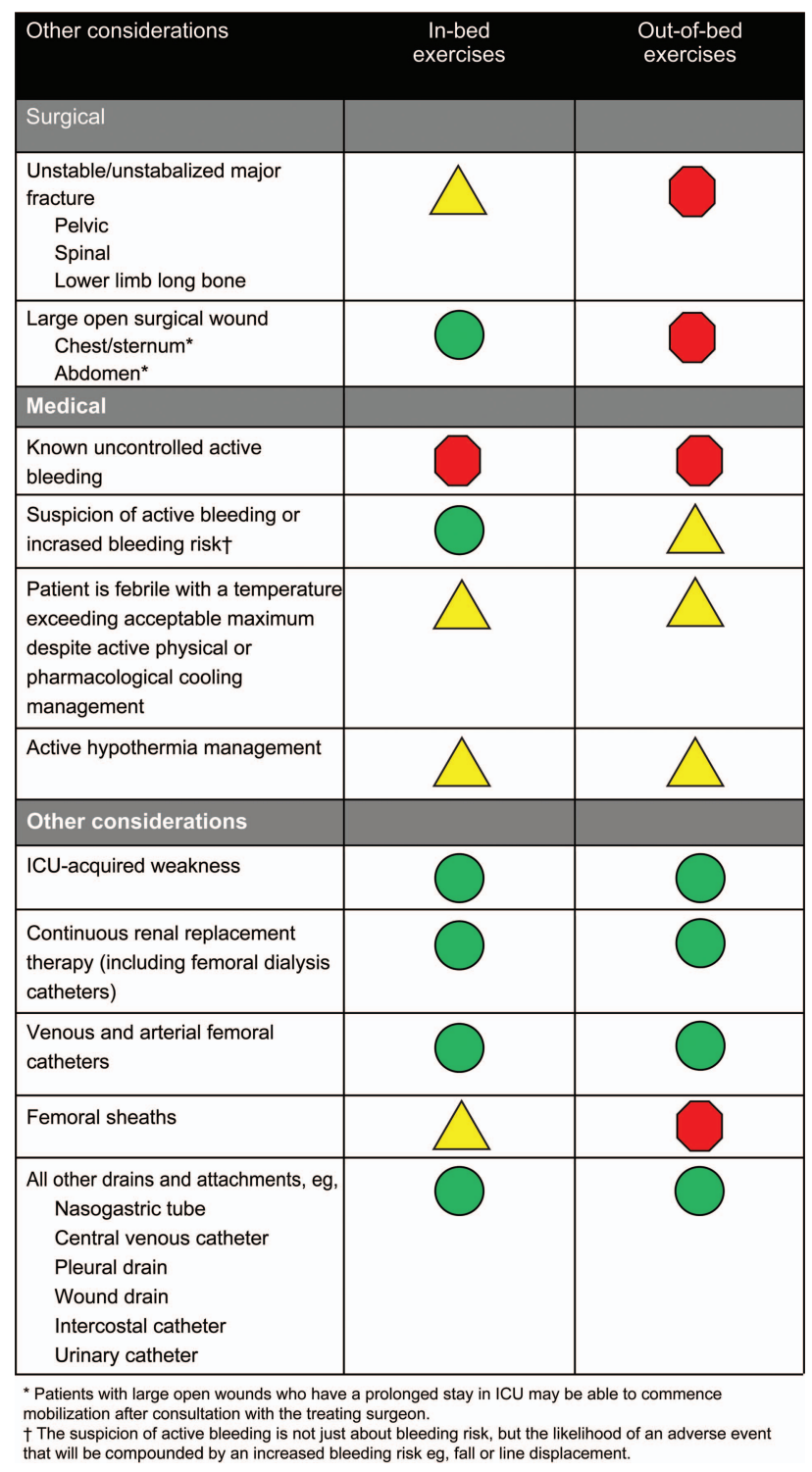

Fig. 6. Other considerations for early mobility. For color coding definitions, see Figure 2. From Reference 14, with permission.

which provided $5-\mathrm{d} /$ week mobility capabilities, one physical therapist and one part-time aid were added. An ICU platform walker was also required. Thus, up to 6 additional new personnel needed to be hired to carry out these programs, and often some additional equipment is required. The bottom line is that these programs are not free, and administration must buy into these additional resources to allow these programs to exist.

\section{Other Logistical Challenges}

In 2011, Garzon-Serrano et al ${ }^{19}$ identified some important barriers to physical therapy in the ICU. The most commonly identified barriers were continuous renal re- placement therapy, hemodynamic instability, and neurologic impairment. This is in accordance with other studies in naming hemodynamic and respiratory instability and sedation as major barriers to initiating physical therapy in the ICU. ${ }^{8-10}$ These barriers must be addressed for a mobility program to be successful.

\section{Conclusions}

Functional disability after critical illness can be a major problem for patients. ${ }^{21}$ Although survival from the ICU has improved greatly in the last $30 \mathrm{y}$, these patients continue to have poor long-term physical outcomes. ICUacquired weakness is implicated in causing many patients' poor physical outcomes. Multiple studies have shown that immobility during bed rest and the inflammatory response during critical illness are associated with the development of ICU-acquired weakness. Unfortunately, in most ICUs across the world, patients who require prolonged mechanical ventilation are still kept on bed rest while recovering.

This article outlines the argument in favor of implementing early mobilization as a candidate for reducing ICU-acquired weakness. When performed in the right patient population, early physical mobility is both safe and feasible. Early mobility has been shown to reduce hospital costs by reducing the stay in both the ICU and hospital and reducing chronic debilitation and health complications. Early mobilization arguably may require increased resources but can be cost-effective if implemented correctly with a specific mobility team. Concerns and cautions to early mobility exist, and careful thought should go into patient selection and monitoring, given these concerns. Despite these cautions, however, there seems to be very little down side to early mobilization in mechanically ventilated patients in the ICU, and its implementation could change the face of post-critical illness life for patients worldwide.

\section{REFERENCES}

1. Fan E, Cheek F, Chlan L, Gosselink R, Hart N, Herridge MS, et al. An official American Thoracic Society Clinical Practice guideline: the diagnosis of intensive care unit-acquired weakness in adults. Am J Respir Crit Care Med 2014;190(12):1437-1446.

2. Lipshutz AK, Gropper MA. Acquired neuromuscular weakness and early mobilization in the intensive care unit. Anesthesiology 2013; 118(1):202-215.

3. Herridge MS, Cheung AM, Tansey CM, Matte-Martyn A, Diaz-Granados N, Al-Saidi F, et al. One-year outcomes in survivors of the acute respiratory distress syndrome. N Engl J Med 2003;348(8):683-693.

4. Truong AD, Fan E, Brower RG, Needham DM. Bench-to-bedside review: mobilizing patients in the intensive care unit-from pathophysiology to clinical trials. Crit Care 2009;13(4):216.

5. Fink H, Helming M, Unterbuchner C, Lenz A, Neff F, Martyn JA, Blobner M. Systemic inflammatory response syndrome increases immobility-induced neuromuscular weakness. Crit Care Med 2008; 36(3):910-916. 


\section{Early Mobilization in Mechanically Ventilated Patients}

6. De Jonghe B, Sharshar T, Lefaucheur JP, Authier FJ, Durand-Zaleski I, Boussarsar M, et al. Paresis acquired in the intensive care unit: a prospective multicenter study. Jama 2002;288(22):2859-2867.

7. Griffiths RD, Palmer TE, Helliwell T, MacLennan P, MacMillan RR. Effect of passive stretching on the wasting of muscle in the critically ill. Nutrition 1995;11(5):428-432.

8. Bailey P, Thomsen GE, Spuhler VJ, Blair R, Jewkes J, Bezdjian L, et al. Early activity is feasible and safe in respiratory failure patients. Crit Care Med 2007;35(1):139-145.

9. Morris PE, Goad A, Thompson C, Taylor K, Harry B, Passmore L, et al. Early intensive care unit mobility therapy in the treatment of acute respiratory failure. Crit Care Med 2008;36(8):2238-2243.

10. Schweickert WD, Pohlman MC, Pohlman AS, Nigos C, Pawlik AJ, Esbrook CL, et al. Early physical and occupational therapy in mechanically ventilated, critically ill patients: a randomised controlled trial. Lancet 2009;373(9678):1874-1882.

11. Morris PE, Griffin L, Berry M, Thompson C, Hite RD, Winkelman $\mathrm{C}$, et al. Receiving early mobility during an intensive care unit admission is a predictor of improved outcomes in acute respiratory failure. Am J Med Sci 2011;341(5):373-377.

12. TEAM Study Investigators, Hodgson C, Bellomo R, Berney S, Bailey $\mathrm{M}, \mathrm{Buhr} \mathrm{H}$, et al. Early mobilization and recovery in mechanically ventilated patients in the ICU: a bi-national, multi-centre, prospective cohort study. Crit Care 2015;19:81.

13. Thomsen GE, Snow GL, Rodriguez L, Hopkins RO. Patients with respiratory failure increase ambulation after transfer to an intensive care unit where early activity is a priority. Crit Care Med 2008;36(4): $1119-1124$
14. Hodgson CL, Stiller K, Needham DM, Tipping CJ, Harrold M, Baldwin $\mathrm{CE}$, et al. Expert consensus and recommendations on safety criteria for active mobilization of mechanically ventilated critically ill adults. Crit Care 2014;18(6):658.

15. Bourdin G, Barbier J, Burle JF, Durante G, Passant S, Vincent B, et al. The feasibility of early physical activity in intensive care unit patients: a prospective observational one-center study. Respir Care 2010;55(4):400-407.

16. Adler J, Malone D. Early mobilization in the intensive care unit: a systematic review. Cardiopulm Phys Ther J 2012;23(1):5-13.

17. Sricharoenchai T, Parker AM, Zanni JM, Nelliot A, Dinglas VD, Needham DM. Safety of physical therapy interventions in critically ill patients: a single-center prospective evaluation of 1110 intensive care unit admissions. J Crit Care 2014;29(3):395-400.

18. Gosselink R, Bott J, Johnson M, Dean E, Nava S, Norrenberg M, et al. Physiotherapy for adult patients with critical illness: recommendations of the European Respiratory Society and European Society of Intensive Care Medicine Task Force on Physiotherapy for Critically Ill Patients. Intensive Care Med 2008;34(7):1188-1199.

19. Garzon-Serrano J, Ryan C, Waak K, Hirschberg R, Tully S, Bittner EA, et al. Early mobilization in critically ill patients: patients' mobilization level depends on health care provider's profession. PM R 2011;3(4):307-313.

20. Engel HJ, Needham DM, Morris PE, Gropper MA. ICU early mobilization: from recommendation to implementation at three medical centers. Crit Care Med 2013;41(9 Suppl 1):S69-S80.

21. Herridge MS, Tansey CM, Matte A, Tomlinson G, Diaz-Granados $\mathrm{N}$, Cooper A, et al. Functional disability 5 years after acute respiratory distress syndrome. N Engl J Med 2011;364(14):1293-1304.

\section{Discussion}

Berra: I have a couple of comments, one is that in our institution we do a lot of early mobilization especially in the surgical and medical units. At the beginning we started with a few people interested in the topic: a few physicians, some nurses and physical therapists (PTs). Sometimes a few residents joined the team in mobilizing patients out of bed. Historically for us, it was crucial to identify a team interested in early mobilization. Over time it became natural for other people to join the early mobilization efforts, other nurses, PTs and respiratory therapists (RTs) in the unit. I was surprised to see how many people joined that study, and how large the team became. I have a question for those of you who do randomized controlled trials (RCTs). As noted it is crucial to have education in this type of intervention. In my opinion an RCT, blinded or not, will not capture the benefit of an intervention such as this one (mostly educational).

MacIntyre: It's impossible in that arena to do a real outcomes study. Those who do it are believers, they are convinced they're doing the right thing and don't have the equipoise to put patients into a control group that doesn't get the intervention. And I'm not sure we should be arguing for more RCTs, I really do think it makes sense and we ought to be doing these things. The studies need to be more on how to do it safely, effectively, and cost-effectively. Selection, monitoring, keeping it as safe as possible, and as inexpensive as possible is where I think the need for more research is.

Kallet: I think the appropriate level of evidence would be a before and after study. I agree that if you try to do an RCT there will be the "John Henry effect"-you see someone who's getting early mobility and you're go- ing to do something that mimics it with patients assigned to the control group. I think it's only human nature to do that. But a before-and-after study done in an institution within a short period of time, practices aren't likely to change that much. So I think you'll get enough persuasive data. The other comment I'd like to make is I sense that with the enthusiasm for this we're going to have some problems with fanaticism. In one of the local hospitals, they were boasting that they took a patient on $30 \mathrm{~cm} \mathrm{H}_{2} \mathrm{O}$ of PEEP and got them sitting in a chair and that was considered progress in the patient's recovery! I had to have my jaw reattached from the floor for that one. They always show a picture of mobilizing someone on a ventilator-we did this back in the early ' 80 s. But patient selection was huge then (as it is now) and I think it's false promotion to constantly show those images of walking a patient on a ventilator down the hall. We need to focus more on real things like passive range of motion, getting 


\section{Early Mobilization in Mechanically Ventilated Patients}

them sitting up in a chair or dangling on the side of the bed. This would probably be much more accurate of what can be done realistically. And not sensationalizing the therapy and inappropriately pushing acutely ill patients to the limit.

MacIntyre: The biggest study ${ }^{1}$ I showed only got $11 \%$ actually walking. But that's OK. I think just getting them to sit up and move around is good. I'll go back to my earlier point, I think this may just be a good prod to reduce sedation.

Kallet: I agree. I suspect the other with asynchrony, is that clinicians just are not thinking things through. You get someone mobilized and they're going to need increased ventilatory support: their minute ventilation demand and work of breathing are going to go up, their sense of dyspnea is going to go up. And this would actually be the perfect segue to proportional assist ventilation. You can't just keep someone on standard spontaneous breathing trial settings and have them getting out of bed or walking up and down the hallway; they'll need a lot more support, initially.

Kacmarek: We do walk patients on extracorporeal membrane oxygenation (ECMO).

MacIntyre: I think mobility with ECMO is often easier than with a ventilator.

Kacmarek: Yes. We've walked them on ECMO and mechanical ventilation. We tried to extubate them but we've had transplant patients where we've still provided ventilator support during ECMO and have walked them. But mostly it's after we've extubated them.

Hess: We talk about this as though we're implementing a new practice, and I guess for many it is a new practice. Back in the 1970s I recall we had a device in our ICU we called the Birdmobile. It was a walker that was outfitted with wheels. It had a Bird Mark 7 on it, it had places on the sides to put $\mathrm{O}_{2}$ tanks, and we would get patients out of bed and manage them on the ventilator wide awake and walk them in the hallway. And then along came pancuronium and propofol and midazolam. Now we talk about how we wake up patients and ambulate them. It's back to the future.

Marini: Can I open up the discussion a little? Why do we think mobilization works? We all believe that it is good for people and most of us say that gravitational forces on the vasculature and muscles would increase tone in both systems, and that's a useful thing. But I think there's something deeper than that. The connection between the perception of getting stronger and healing may be subtle and more powerful than we understand. When patients sense that they're making progress-they're getting out of bed and their family sees them and encourages them-a lot of crosstalk goes on between the brain, muscles, and other body systems. I'm wondering if we're almost putting training wheels back on the whole system, so to speak. Getting them out of the supine position, putting gravitational forces back on their muscles and vascular systems and getting the benefits of variation, being upright and moving. Giving the patient the mental picture of making progress is perhaps encouraging them in a way we don't quite understand yet. Secondly, we have better equipment to get people upright; advanced beds can be adjusted to encourage getting the patient up these days. The labor involved in getting them upright is a lot less and it is less dangerous. I'm an advocate, but I realize there are dangers.

MacIntyre: Going back to my rehab experience, it's very similar to what you just said, John. It's more than making them walk around the track. Yes, that probably does have conditioning effects on both the heart and the skeletal muscles. But the mental encouragement of realizing 'by God I can do this' is as important, if not more important, than the physical training.

Marini: The will to live and encouragement to stop being depressive about their situation. These people often have been knocked flat on their butts by their illnesses, and they need to feel optimism and progress toward a goal. Such mental signals might be more powerful than I previously believed. And early mobilization might help send those.

\section{REFERENCE}

1. Adler J, Malone D. Early mobilization in the ICU: a systematic review. Cardiopulm Phys Ther J 2012; 23:1:4-44. 